Running head: EMOTIONS AND (UN)FAIRNESS IN CHILDREN

Title: The ontogeny of children's social emotions in response to (un)fairness

[STAGE 1 REGISTERED REPORT ACCEPTED IN PRINCIPLE FOR PUBLICATION IN ROYAL SOCIETY OPEN SCIENCE]

Stella Gerdemann ${ }^{1,2}$, Katherine McAuliffe ${ }^{3}$, Peter R. Blake ${ }^{4}$, Daniel B. M. Haun ${ }^{2,5,6}$, Robert Hepach $^{1,2}$

${ }^{1}$ Department of Research Methods in Early Child Development, Leipzig University, Leipzig, Germany

${ }^{2}$ Leipzig Research Center for Early Child Development, Leipzig University, Leipzig, Germany

${ }^{3}$ Department of Psychology, Boston College, Boston, USA

${ }^{4}$ Department of Psychological and Brain Sciences, Boston University, Boston, USA

${ }^{5}$ Department of Early Child Development and Culture, Leipzig University, Leipzig, Germany

${ }^{6}$ Department of Comparative Cultural Psychology, Max Planck Institute for Evolutionary Anthropology, Leipzig, Germany

Corresponding Author: Stella Gerdemann, Faculty of Education at Leipzig University, Jahnallee 59, D-04109 Leipzig, T +49 (0) 3419731 875, stella.gerdemann@uni-leipzig.de 
EMOTIONS AND (UN)FAIRNESS IN CHILDREN

Data Availability: All final data and analysis scripts will be made available on the Open

Science Framework upon publication the current study. The pilot data and analysis scripts can be accessed through the Open Science Framework: https://osf.io/xem8k/.

Acknowledgements: We thank the participating children and their parents, and Theo Toppe for helpful comments on an earlier draft of this manuscript.

Conflict of Interest Statement: None to declare. 
EMOTIONS AND (UN)FAIRNESS IN CHILDREN

\begin{abstract}
Humans have a deeply-rooted sense of fairness, but its emotional foundation in early ontogeny remains poorly understood. Here, we ask if and when children show negative social emotions, such as shame or guilt, in response to advantageous unfairness expressed through a lowered body posture (measured using a Kinect depth sensor imaging camera). We will present young children across the age range of 4 to 9 years with a scenario in which one child (the actor) chooses between two opaque boxes each containing rewards. We then manipulate whether the actor's box contains 4 rewards or 1 reward (while the other box always contains 1) and measure children's emotional expression. In a nonsocial context, i.e., when the resource distribution affects only the acting child, we expect that children will express a positive emotion (an elevated posture) after receiving 4 rewards and a negative emotion (a lowered posture) after receiving 1 reward. The crucial question we ask is if and when in ontogeny children express social emotions in response to (un)fairness. In a social context, i.e., when the reward distribution affects the acting child and a peer recipient, receiving 4 rewards while a peer receives 1 reward should result in a negative social emotion similar to shame or guilt (lowered posture), whereas a 1-1 fair split should result in a positive emotion similar to pride (elevated posture). The systematic study of children's social emotions across a wide age range will shed new light on emotional foundation of the human sense of fairness.
\end{abstract}

Keywords: Inequity aversion, social emotions, Kinect, fairness, body posture 
EMOTIONS AND (UN)FAIRNESS IN CHILDREN

\section{The ontogeny of children's social emotions in response to (un)fairness}

A concern for fairness when distributing resources is considered a bedrock for human cooperation (Fehr \& Fischbacher, 2003). When need or effort between individuals are similar, adults show inequity aversion (Fehr \& Schmidt, 1999), that is negative emotional and behavioral responses to unequal divisions of resources, both in the context of disadvantageous inequity when given comparably less than another, as well as in the case of advantageous inequity when given relatively more (Dawes, Fowler, Johnson, McElreath, \& Smirnov, 2007; Güth, Schmittberger, \& Schwarze, 1982; Henrich et al., 2010, 2006; Loewenstein, Thompson, \& Bazerman, 1989). While disadvantageous resource distributions are rejected more often when a social partner receives more, disadvantageously unequal resource are also rejected in nonsocial contexts, when no recipient's stake is affected by the resource distribution (McAuliffe, Blake, Kim, Wrangham, \& Warneken, 2013, Sanfey, Rilling, Aronson, Nystrom, \& Cohen, 2003). This suggests that disadvantageous inequity aversion may be motivated by fairness concerns, as well as a nonsocial frustration over receiving less than one could. By contrast, advantageous inequity aversion requires resolving a conflict between nonsocial concerns (for gaining more than a fair share of a resource for oneself) and fairness norms (equitable distribution of resources), as these two motives are not aligned when receiving more than one deserves (Engelmann \& Tomasello, 2019). Social emotions, such as shame, guilt and pride, are theorized to have the evolved function of enabling humans to resolve such conflicts between self-interest and social norms, to the degree that they are internalized forms of an evaluation of oneself and one's behavior as viewed from the perspective of one's social group (e.g., Tomasello \& Vaish, 2013). This raises the question if and when during ontogeny children show negative social emotions, such as shame or guilt, in response to advantageous inequity, and positive social emotions, such as pride, in response to fairness. 
EMOTIONS AND (UN)FAIRNESS IN CHILDREN

When self-interest is not at stake, in third-party contexts, 3-year-old children divide resources fairly between others, that is equally or according to merit (Baumard, Mascaro, \& Chevallier, 2012; Olson \& Spelke, 2008). Similarly, in first party contexts, young children by age 4 show disadvantageous inequity aversion (Blake \& McAuliffe, 2011; Fehr, Bernhard, \& Rockenbach, 2008; McAuliffe et al., 2013; Sheskin, Bloom, \& Wynn, 2014). For instance, when resources are divided unequally between peers, such as through a $(1,4)$ distribution, young children reject this distribution entirely and discard it into a trash bin (Blake \& McAuliffe, 2011). Yet, advantageous inequity aversion, by contrast, does not appear to emerge until children are at least school-aged, and its development shows more variability across cultures than disadvantageous inequity aversion (Blake \& McAuliffe, 2011; Blake et al., 2015; Dunham, Durkin, \& Tyler, 2018; Fehr, Bernhard, \& Rockenbach, 2008; House et al., 2019, 2013; Shaw \& Olson, 2012 see McAuliffe, Blake, Steinbeis, \& Warneken, 2017 for a review). For instance, by age 7, children from US-American samples will rather throw an additional resource away, if receiving it would make an equal split unequal in favor of themselves (Shaw \& Olson, 2012; Dunham et al., 2018). In these studies children younger than age 7 appear either indifferent to the lack of fairness towards others or may prefer selfadvantaging inequity. Thus, one study showed that 5- to 6-year-olds will take a cost to avoid fairness and disadvantage a peer, showing "anti-equality" (Sheskin et al., 2014). Given that children are aware of fairness norms by age 3 (Smith, Blake, \& Harris, 2013), it appears unlikely that young children's acceptance of advantageous inequity in many contexts is due to a lack of knowledge of fairness principles.

However, one issue with these studies is that there may be competing task demands that mask children's otherwise negative responses to advantageous inequity. Young children's acceptance of unfairness towards others may partially be the result of younger children's greater difficulty to inhibit a dominant response to accept large quantities of a resource, and thus may be the result of a lack of behavioral control (Steinbeis, 2018; Steinbeis, Bernhardt, 


\section{EMOTIONS AND (UN)FAIRNESS IN CHILDREN}

\& Singer, 2012, although see also Smith et al., 2013). Moreover, in contexts in which resources are acquired collaboratively by peers without a proposed unequal resource distribution by an adult, young children divide resources fairly when doing so requires giving up an advantage (Hamann, Bender, \& Tomasello, 2014; Hamann, Warneken, Greenberg, \& Tomasello, 2011; Ulber, Hamann, \& Tomasello, 2017; see also Corbit, McAuliffe, Callaghan, Blake, \& Warneken, 2017). However, only older children reject advantageous resource distributions acquired through windfall (Blake \& McAuliffe, 2011; Shaw \& Olson, 2012). Given the, in part, contradictory results across studies and contexts regarding children's behavior in response to advantageous inequity, here, we will systematically investigate the development of children's social emotions in response to (un)fairness.

Despite the relevance of social emotions, such as shame, guilt and pride, to following social norms and overriding ones' self-interest (Tomasello \& Vaish, 2013), little empirical work has focused on the development of children's social emotions in response to (advantageous) (un)fairness. In one study, Kogut (2012) found that children by fourth grade, but not younger children, report being less satisfied following self-advantaging compared to equal distributions of resources after sharing with another child. One potential reason that children below grade four might not have reported different emotions to self-advantaging compared equal outcomes in this study is that recipients were absent and anonymous peers. In support of this view, young children's fairness-related behavior increases when recipients are present compared to when they are absent (House, Henrich, Brosnan, \& Silk, 2012).

In the - to our knowledge - only study, which examined children's spontaneous facial expressions of emotion in response to (un)fairness in a peer context, LoBue, Nishida, Chiong, DeLoache, \& Haidt (2011) found that 3- to 5-year-old children respond with negative emotions to receiving less of a resource than a peer, yet with neutral to positive emotions to receiving more. Relatedly, although both younger and older children are aware of the impermissibility of violations of social norms, younger children, between age 4 to 6 , have 


\section{EMOTIONS AND (UN)FAIRNESS IN CHILDREN}

been found to attribute positive emotions to third parties and themselves in hypothetical scenarios involving transgressions against social norms (e.g., when stealing candy from another child), thus behaving as "happy victimizers" (Keller, Lourenço, Malti, \& Saalbach, 2003; Krettenauer, Malti, \& Sokol, 2008; Nunner-Winkler \& Sodian, 1988; Pons, Harris \& \& Rosnay, 2004). Only older children, by age 7 to 9 , more consistently attribute negative emotions to transgressors and themselves in such scenarios (e.g., Keller et al., 2003). The overall conclusion from this line of work is that young children are aware of fairness norms from an impartial third-party point of view and respond with negative emotions to disadvantageous inequity. Yet, young children may not, at an early age, experience fairness norms as personally binding to the degree that they express negative emotions when a resource distribution advantages them.

A perhaps critical methodological difference between the study by LoBue et al. (2011), and prior work on children's social emotions is that children in this study did not cause the negative outcome (i.e., the unfairness) themselves, and rather merely witnessed an adult causing it. Yet, viewing the self, rather than another, as the source of a negative or positive outcome is a central antecedent of social emotions such as guilt, shame and pride (Lewis, 2007; Stipek, Recchia, McClintic, \& Lewis, 1992; Vaish, Carpenter, \& Tomasello, 2016). For instance, 3-year-olds are more likely to show guilt-like responses when they cause harm to another compared to when no harm is caused or the harm is caused by a third party (Vaish et al., 2016). Moreover, by age 4 to 6, preschoolers attribute negative, rather than positive, emotions to transgressors who unintentionally violate social norms (Nunner-Winkler \& Sodian, 1988). Consistent with this prior work on children's social emotions, negative emotions to advantageous inequity may be stronger when children unintentionally cause, rather than passively witness, an advantageous resource allocation. In addition, despite extensive work documenting that adults and children often express social emotions through the body - with an elevated body posture signaling positive social emotions, and a lowered 
EMOTIONS AND (UN)FAIRNESS IN CHILDREN

body posture indicating negative social emotions (App, McIntosh, Reed, \& Hertenstein, 2011; Keltner \& Harker, 1998; Kochanska, Gross, Lin, \& Nichols, 2002; Lewis, Alessandri, \& Sullivan, 1992; Tracy \& Matsumoto, 2008; Wallbott, 1998; see Witkower \& Tracy, 2018 for a review) - no previous work has examined whether children express social emotions to (un)fairness through their body posture.

Here, we will assess children's emotions, expressed through their body posture elevation, following equal $(1,1)$ and unequal $(4,1$; advantageous) distributions of resources (within-subjects factor). We plan to test children between the age of 4 to 9 years (based on McAuliffe et al., 2013; Dunham et al., 2018). In a social context, children will divide resources between themselves and a same-aged peer, rendering the resource distributions either fair $(1,1)$ or unfair in favor of the child in focus $(4,1)$. In a nonsocial control context, children will divide resources between themselves and a container "for resources that no one will receive at the end of the game" rendering the resource distributions merely equal $(1,1)$ or unequal $(4,1)$.

The general design of the current study involves the child in focus (the actor) dividing resource boxes which contain different quantities of a resource (either 4 stickers or 1 sticker). Prior to deciding how to divide these resource boxes between themselves and their peer (social context) or a container (nonsocial context), actors are ignorant with regards to the contents of the boxes. After the actor has decided how to divide the resource boxes, children find out whether the actors' choice created an equal or unequal split (see also O'Connor, McCormack, \& Feeney, 2012; Weisberg \& Beck, 2012 for similar manipulations). Choosing boxes from a position of ignorance with regards to their content, might lead adults to perceive the outcome as the result of luck, which may lead to a blunted emotional response. However, it appears that having some form of responsibility for a negative outcome, even if it is illusory (e.g., if the outcome is decided on by rolling a die), can lead to negative emotions in children (Weisberg \& Beck, 2012). Shortly following the equal and unequal resource distributions, 
EMOTIONS AND (UN)FAIRNESS IN CHILDREN

children's body posture is measured by means of a depth sensor imaging camera (Kinect, (C)Microsoft) which allows for an objective examination of the change in children's emotions (Hepach, Vaish, \& Tomasello, 2015, 2017).

\section{Hypotheses}

In sum, we plan to systematically examine if children show a more negative social emotion in response to advantageous inequity than in response to equal distributions of resources expressed through a change in their body posture elevation. Regarding the development of children's emotions, we have two broad hypotheses. If only older children (by age 7 to 9) respond with negative social emotions to advantageous inequity, children by this age - but not younger children - should show more negative emotions to $(4,1)$ than to $(1,1)$ distributions in the social context (H1: Behavior and emotion co-emerge). This hypothesis is supported by a large body of work showing that children by this age, but not before, reject advantageous resource allocations (e.g., Blake \& McAuliffe, 2011; Dunham et al., 2018). Alternatively, if younger and older children show similar social emotions in response to advantageous inequity, then children across the entire age range should respond with more negative emotions to $(4,1)$ than to $(1,1)$ distributions in the social context $(H 2$ : Emotion precedes behavior).

Next, we highlight more specific potential patterns of data that could emerge from the current study (see also S3, Supplementary Materials). First, in the nonsocial context children are predicted to respond with positive emotions to gaining a greater share of a resource on $(4,1)$ trials and more negative emotions in response to receiving a smaller share of a resource on (1,1) trials (O'Connor et al., 2012; Weisberg \& Beck, 2012). Consistent with the literature on the development of relief and regret, there may be age-related changes in children's emotional responses to receiving more or less than they could have in the nonsocial context (see Beck \& Riggs, 2014 for a review). It is currently unclear when precisely children begin to feel emotions such as relief and regret, as some studies suggest that regret emerges as early 


\section{EMOTIONS AND (UN)FAIRNESS IN CHILDREN}

as age 4 to 5 (Weisberg \& Beck, 2012), while other studies find that children do not show regret until they are age 6 to 7 (O'Connor et al., 2012). Moreover, in most studies, relief has emerged later during development than regret (Beck \& Riggs, 2014). Yet these studies converge on the finding that, if there is a developmental change in the emotions relief and regret between age 4 to 9 , then children's positive emotions to receiving more and negative emotions to receiving less than they could have in nonsocial contexts ought to increase with age, as they become more similar to the adult versions of these emotions.

In the social context, $H 1$ and $H 2$ make different predictions only regarding the emotional responses of younger children. Both hypotheses predict that older children by age 7 to 9 , will respond with a more negative emotion to disadvantaging a peer than to equal distribution of resources. For children below age 4 to 6 , two data patterns are consistent with H1: Emotion and behavior co-emerge. First, consistent with the findings of Kogut (2012), young children may respond with a similar emotion to unequal and equal distributions of resources or, alternatively, consistent with the findings of LoBue et al. (2011), young children might respond with more positive emotions to gaining more of a resource on $(4,1)$ trials compared to $(1,1)$ trials in the social context. By contrast, H2: Emotion precedes behavior predicts that already young children, by age 4 to 6 , respond with more negative emotions to advantageous inequity than to equal resource distributions.

Following the emotion-eliciting phase, children will participate in a short behavioral paradigm to assess their willingness to pay a cost to avoid advantageous inequity. Like in a large body of previous work (e.g., Blake \& McAuliffe, 2011; Dunham et al., 2018; Fehr et al., 2008; Shaw \& Olson, 2012), here, we expect only older children (by age 7 to 9) to reject advantageous resource distribution in the social context (H3: Late emergence of behavior). The reason for including this measure is to provide an outcome-neutral control that the value, ratio and resource chosen are able to elicit a rejection of advantageous inequity, an established measure for inequity aversion, in the current sample of children. 


\section{General Method}

We plan to measure children's emotions by means of a depth sensor imaging camera (Kinect). This camera, operated through a script run in Matlab (Version 9.5), records the x-, yand z-coordinates of 20 body posture joints at regular intervals during recorded sequences. In subsequent processing steps, sequences during which children are walking towards the camera, are selected based on an algorithm developed by Hepach et al. (2017). During the study, 3 baseline recordings, as well as 8 test recordings ( 4 following equal, and 4 following unequal resource distributions) are created of the actors while they walk towards the Kinect camera. The analyses focus on children's baseline-corrected chest height (the y-value of the chest center data point) and baseline-corrected hip height (the y-value of the hip center data point) during the test recordings (Hepach et al., 2015; 2017). Since children do not provide an equal number of data points for each recording, missing values are filled by an interpolation algorithm.

The Kinect system, as well as the algorithms designed to extract valid sequences, provide objective measures of relatively small changes (e.g., as small as $1 \mathrm{~cm}$ ) in postural elevation. For instance, Hepach et al. (2015) showed that children's posture is lowered when they fail to achieve a positive outcome for themselves, and more elevated when they receive a fun reward to play a game. Similarly, this validation study showed that adults' posture is more slumped when they imagine negative emotions compared to positive ones. More importantly, currently ongoing work using this method has shown that 5-year-old children's body posture is more slumped in response to not helping (Gerdemann, Tippmann, Dietrich, Engelmann, \& Hepach, in preparation), providing proof of concept that the methodological approach is able to show children's postural decrease in prototypical guilt- or shame-eliciting situation. While the Kinect camera provides a useful tool to examine changes in children's emotions ranging from more positive to more negative, it is important to note that the body posture outcome 
EMOTIONS AND (UN)FAIRNESS IN CHILDREN

measures do not objectively differentiate specific emotions (e.g., disappointment from shame), which can only be accomplished by considering the context in which an emotion was expressed.

\section{Method}

\section{Ethical Approval}

This study is approved by the ethics committee of the medical faculty of Leipzig University (IRB number: 169/17). Children whose parents have signed a consent form for their child's participation will be included in the sample.

\section{Timeline}

The proposed timeline for data collection and to submit the final stage 2 manuscript is 12 months.

\section{Participants}

Participants will be $\mathrm{N}=192$ subject children (actors), between the age of 4;0-9;11. $\mathrm{N}=96$ children will participate in each between-subjects condition (context: social or nonsocial) approximately evenly distributed across the entire age range. In the social context, actors will participate with recipients of approximately the same age (within a range of $+/-1.5$ years age difference) and the same gender $(\mathrm{N}=96)$. Children will be recruited from the same kindergarten or school, and randomly assigned to their respective role within the dyad. Other than gender and age there will be no additional criteria for assigning children to dyads. We piloted a version in which data was collected from actors and recipients, however, having both children take turns walking towards the Kinect resulted in an increased study duration, which lead to children becoming increasingly inattentive. To be included in the sample actors (a) need to complete the study (i.e., complete all body posture trials, and the behavioral measure of advantageous inequity aversion), and (b) have at least two valid test trials per within-subjects condition. Trials will be considered invalid (a) if they feature a wrong 
EMOTIONS AND (UN)FAIRNESS IN CHILDREN

distribution (e.g., $[1,4]$, instead of $[4,1])$, which will be determined offline from the video recordings of the test sessions by a blind coder, or (b) if no body posture data is available, either because of equipment failure or because no upright skeleton could be mapped (see also Hepach et al., 2017). Children who are excluded due to these criteria will be replaced until the sample size of $\mathrm{N}=192$ is reached.

\section{Materials and Design}

This study is based on a mixed design with the between-subjects factor context (social or nonsocial) and the within-subjects factor distribution (equal or unequal). Equal distributions will create a $(1,1)$ split and unequal ones will create a $(4,1)$ split, which will always favor the subject child in focus. The final choice of these resource allocations was the result of piloting the procedure with children across a wide age range.

During the emotion-eliciting part, children will first participate in an introductory phase (two demonstration trials and one practice trial), followed by a test phase (eight test trials, four with an equal, and four with an unequal distribution). The order of the equal and unequal test trials will be blocked (each child will receive four trials of the same test trial type in succession followed by four of the other test trial type) and counterbalanced across participants. The blocked design was a result of piloting the procedure, as it appeared most suitable to isolate children's emotions in response to the within-subjects conditions. The dependent measure will be children's change in upper body posture following the experimental manipulations. During a post-test phase, a behavioral measure of advantageous inequity aversion will be collected (Blake \& McAuliffe, 2011; Shaw \& Olson, 2012).

Children will receive one trial with a proposed $(4,1)$ distribution, and choices will be coded as 1 (reject; leave resources in the boxes) or 0 (accept; distribute). In addition, as part of efforts to further validate the Kinect method children will participate in short post-test interview. Children's responses to the post-test interview questions will not be used to directly address the hypotheses, and will be reported in a separate section on exploratory analyses. 
EMOTIONS AND (UN)FAIRNESS IN CHILDREN

The resources will be equally-sized colorful smiley stickers (Dunham et al., 2018; LoBue et al., 2011). Each trial will feature a set of resource boxes placed into larger square distribution boxes creating distribution packages of two resource boxes each. The resource boxes, which contain the stickers for each trial, have two compartments, i.e., a double-bottom, allowing the experimenter, E1, to rig the distribution by flipping the resource boxes vertically (see Figure 2). The distribution boxes will be positioned on a resource table and retrieved by the actor during the study. In total, actors will retrieve twelve distribution boxes from the resource table: three for the introductory trials, eight for the test trials, and one dummy distribution box, which is retrieved following the last test trial, so that actors provide a final test body posture recording. The distribution boxes for the test trials are placed on colored trays, so that actors can be instructed regarding which distribution box to pick for each test trial. Children will interact with each other and E1 at a separate study table which will be approximately 4,5 meters from the resource table. On the study table there will be two game plates, onto which the resource distributions will be placed on each trial, as well as collection plates for children to collect their resources after each trial. In the nonsocial context, children will see an opaque container with additional resources in it. For the behavioral measure of advantageous inequity aversion, resources will be placed into a set of separate resource boxes (see also S1, Supplementary Materials). In addition, only in the social context, next to the two chairs for the actor and recipient, there will be two additional chairs with cardboard screens attached to them (see Figure S2, Supplementary Materials). The chair in front of the actor will be removed, once a coin flip has decided which child will become the actor. The other chair will remain in front of the recipient for the remainder of the study, to ensure that only the actor's body posture is recorded by the Kinect camera. 


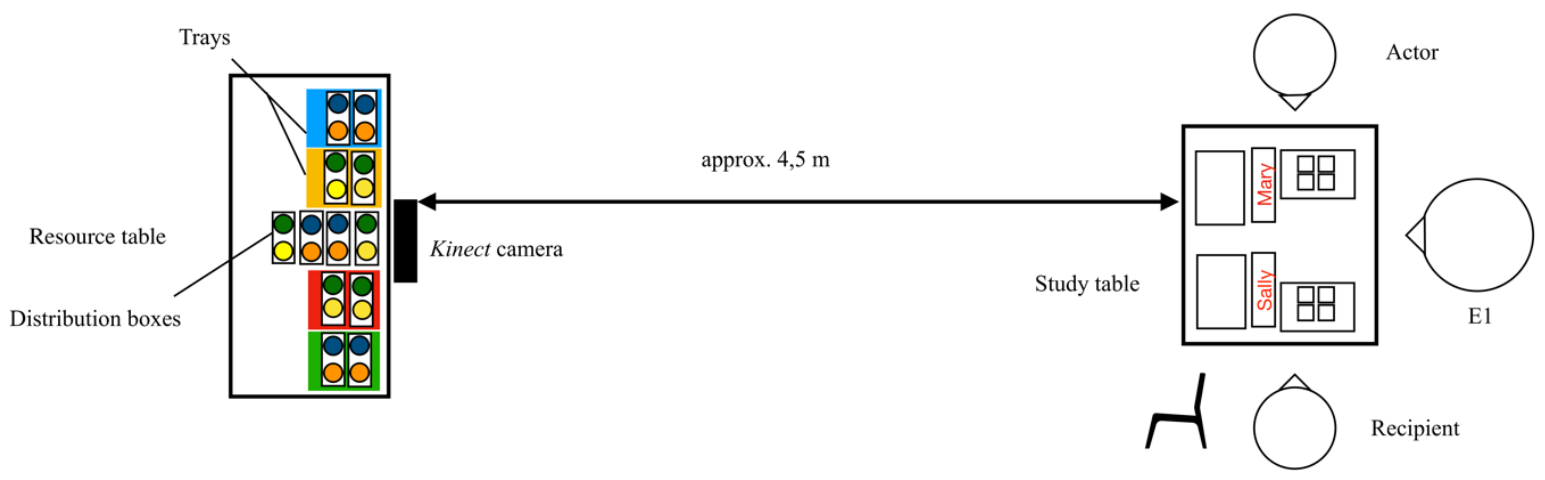

Figure 1. A schematic depiction study set-up from a bird's eye perspective. The actor and recipient sit facing each other at the study table. In the nonsocial context, instead of the recipient, a transparent container is placed on the side opposite the actor. The distribution boxes (and resource boxes) are placed on a resource table on the far side of the room. The Kinect camera records actors' body posture while retrieving distribution boxes from the resource table.

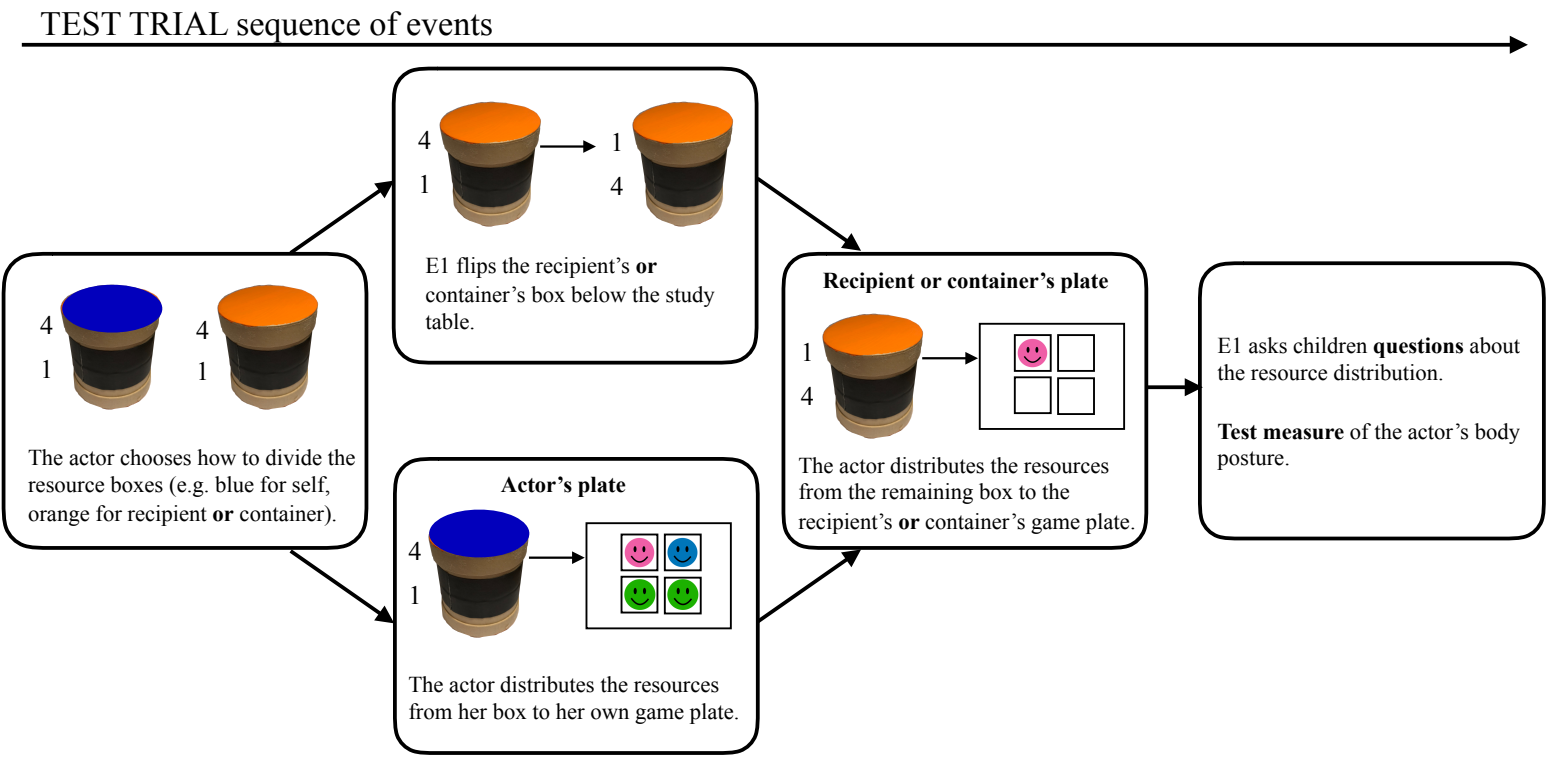

Figure 2. A schematic depiction of the sequence of events during each test trial (an unequal trial is depicted). Initially, two resource boxes contain the same number of resources in both the top (4) and bottom compartments (1). After the actor chooses a resource box for each child or herself and the container, the actor opens her own resource box and distributes the stickers from the top compartment to her game plate. Simultaneously, E1 flips the recipient or 
EMOTIONS AND (UN)FAIRNESS IN CHILDREN

container's resource box, so that instead of 4 stickers the top compartment of the recipient or container's resource box now contains 1 sticker. The actor opens the recipient or container's resource box and distributes the stickers from the top compartment to the recipient or container's game plate.

\section{Procedure}

The study is conducted by two experimenters, E1, who interacts with the children, and E2, who operates the Kinect camera from a laptop. Testing will take place in a quiet room in children's kindergarten or school.

Introductory phase. In the social context, children will participate in dyads, and will be told that they will be able to collect stickers, which are placed on a table on the far side of the room (see also S2, Supplementary Materials for a detailed study script). Children are further informed that they will be asked questions while the resources are distributed, which they will be allowed to answer, but that it is a "quiet game" otherwise. Instructing children not to talk during the study should ensure that any potential effect the disadvantaged recipient's reactions to the actor's resource distributions are comparable across dyads. Following this, a coin flip will determine which child will become the actor. The other child then will become the recipient. In the nonsocial context, the single child will become the actor. In the social context, E1 will briefly remove the chair placed in front of the actor, while the second chair will block the recipient from the point of view of the Kinect. Then, the actor will be asked to retrieve three distribution boxes in succession from the resource table. These will contain the resource distributions for the introductory trials. While the actor walks towards the resource table, three baseline recordings of the actor's body posture will be taken. Each distribution box for the introductory trials will have a different symbol on it. Children will be shown each symbol and asked to retrieve the distribution box with the respective symbol on it before 
walking towards the resource table. These symbols also enable E1 to identify the distribution boxes which contain the correct distribution for the respective introductory trial.

In the social context, E1 will explain that each child will get the stickers out of one resource box, and that some contain four stickers while others contain one. Further, children will be told that, in the game, they each can first place their stickers on their game plates with one sticker occupying a single square, and then move them to their collection plate, where they can collect stickers to take home at the end of the game. E1 will write each child's name below their respective collection plates, as a visual reminder of which one belongs to them. In the nonsocial context, the instructions will be identical, only that an opaque container with more stickers will be placed in the position of the collection plate of the recipient. Children will be told that no one will get the resources that go back into the container. Following this, children will receive three introductory trials, consisting of two demonstrations of the resource distribution by $\mathrm{E} 1$, one with a (4,1; advantageous) distribution, and one with a $(1,4$; disadvantageous) distribution (order counterbalanced across participants). In addition, the actor will receive one practice trial, on which she can decide how the resource boxes should be divided. For the practice trial the distribution will be equal $(1,1)$.

During the practice trial and all following test trials, the actor will be asked how the resource boxes should be divided, thus making actors responsible for the outcome (see Weisberg \& Beck, 2012 for the effect of such manipulations on children's emotions in nonsocial contexts). Thus, in the social context, children will be asked: "Which one should be for (recipient name), the yellow/orange or green/blue box?", and in the nonsocial context: "Which one should go back into the container, the yellow/orange or green/blue box?" Following the actor's choice of resource box for the recipient or the container, actors will be allowed to open the resource boxes and distribute their contents to their own and the recipient's (social context) or the container's (nonsocial context) game plate. 
EMOTIONS AND (UN)FAIRNESS IN CHILDREN

Following the resource distribution, children will be asked questions regarding the resource distribution. In the social context, children will be asked to indicate how many stickers they got, whether one child got more, and if so, who did. These questions are designed to prompt children to attend both to their outcome and that of the other child and evaluate the (un)fairness of the resource distribution. In the nonsocial context children will be asked analogous questions, i.e., how many stickers they got, how many will be returned to the container, and whether there are more stickers on either the child's game plate or the one with stickers that will be returned to the container. Piloting indicated that children nearly always answer these questions correctly, yet, if children answer any of these questions incorrectly, the question will be repeated, and, if necessary, children will be corrected. Additionally, in the nonsocial context, children will be asked a comprehension question to ensure their understanding of the container: "What will happen with the stickers that are in the container at the end of the game?" If children answer this question incorrectly, they will be corrected (see McAuliffe et al., 2013).

Test phase. Before and after each test trial, the actor will be instructed to retrieve a new distribution box from one of the colored trays (from left to right on the resource table). Once actors have retrieved a new distribution box, they will be asked to pick a resource box for each child (social context) or for themselves and the container (nonsocial context) and distribute the resources to the children's or the container's respective game plates. Crucially, the distribution boxes on unequal $(4,1)$ test trials will be manipulated, so that the top compartments of the resource boxes each contain four stickers, and the bottom compartments each contain one sticker. Following the actor's choice regarding how the resource boxes should be divided, E1 will surreptitiously manipulate the recipient's or the container's resource box by briefly removing it from the table and flipping it vertically below the study table, and outside of children's view. The result of this manipulation is that, on unequal trials, the top compartment of the recipient's or the container's resource box always contains one 
EMOTIONS AND (UN)FAIRNESS IN CHILDREN

sticker instead of four, while the top compartment of the actor's resource box will still contain four stickers (see Figure 2). The resource box for the recipient or container will be flipped on both equal and unequal test trials. On equal test trials all compartments of the resource boxes will contain one sticker. During piloting, it was determined that children did not notice that E1 rigged the distribution, as no child commented on the brief removal of the resource box for the recipient or container by E1.

Shortly following each test trial, the actor will be asked to walk towards the resource table to retrieve the distribution box for the next test trial. During this time test recordings of the actor's body posture will be taken. The study will continue in the same manner for the next seven test trials. After the last test trial, when there are no more test distribution boxes left on the resource table, the actor will be asked to retrieve a dummy distribution box to provide the last test body posture recording. This distribution box will contain an equal $(1,1)$ distribution.

Post-test phase. Next, a behavioral measure of actors' advantageous inequity aversion will be collected. The actor will be shown two new resource boxes. Actors will be told that one box (the yellow one) contains four stickers for themselves and that the other box (the green one) contains one sticker for the recipient (social context) or that will be returned to the container (nonsocial context). The lids of the boxes will be lifted briefly to allow children to see how many resources are in each box. The actor will be asked if E1 should [1: distribute them/the stickers] or should [2: leave them/the stickers in the boxes]. These order of answer options 1 and 2 will be counterbalanced across participants. This behavioral measure of advantageous inequity aversion parallels inequity aversion paradigms described in Blake \& McAuliffe (2011) and Shaw \& Olson (2012), which show that children reject advantageous distributions of resources by age 7 to 9 .

In addition, a post-test interview will be conducted. Another unequal $(4,1)$ and equal $(1,1)$ distribution will be created (order identical to the block order during the test phase) and 
the actor will be asked for each one "How did you feel when the distribution was like this?" with the options "good", "rather good", "rather bad" and "bad" (see Harris, Donnelly, Guz, \& Pitt-Watson, 1986).

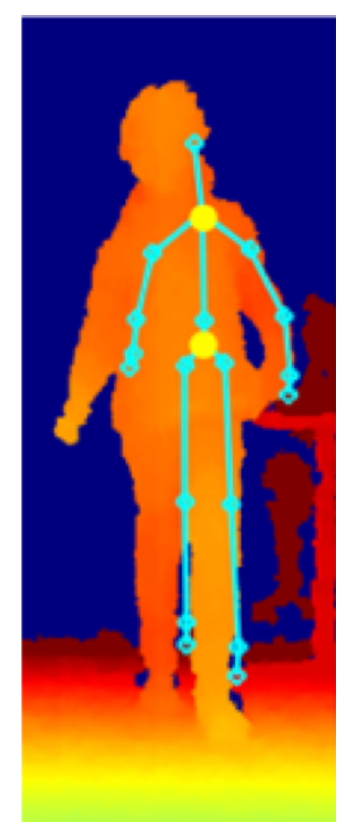

Figure 3. An illustration of the depth images provided by the Kinect camera.

\section{Coding of Children's Behavior and Interview Responses}

The first author will code all of children's choices to either accept or reject the advantageous resource distribution. A blind coder, who will be blind to the hypotheses, will code a randomly selected $25 \%$ of videos, and agreement between the first and second coder will be calculated. Children's responses during the post-test interview will be coded by the first author based on whether they fall into one of three categories ("good", "rather good", "rather bad" or "bad") or were incomprehensible. A second coder, who will be blind to the study hypotheses, will code a randomly selected $25 \%$ of responses for agreement.

\section{Analysis}

The analysis scripts for the planned analysis, along with the pilot data, are made available through the Open Science Framework: https://osf.io/xem8k/.

Body posture. The hypotheses regarding the change in children's body posture will be tested using generalized linear mixed models (GLMMs) with a gaussian error structure. 
EMOTIONS AND (UN)FAIRNESS IN CHILDREN

Models will be calculated in R (Version 3.3.3, R Core Team, 2018) and with the package lme4 (Version 1.1 - 15, Bates, Mächler, Bolker, \& Walker, 2015). The dependent measure will be the baseline-corrected y-value of children's chest-center point after the experimental manipulations. A control analysis will be conducted on the baseline-corrected y-value of children's hip-center point after the experimental manipulations. We have no hypotheses for the control analysis on children's lower body posture given the stronger evidence for social emotions affecting the upper body (Tracy \& Matsumoto, 2008; Wallbott, 1998; Witkower \& Tracy, 2018). Yet, it is possible that the manipulations show a similar effect on the lower body, given that negative social emotions may also elicit a bent-knee gait (Fessler, 2007). The significance of the predictors will be determined based on likelihood-ratio tests calculated with the function dropl() with the alpha level for statistical significance set at $p<.05$. This analysis strategy parallels previous applications of body posture analyses (Hepach et al., 2017).

All models will include random effects for trial, children's school or kindergarten, participant, as well as for children's distance from the Kinect camera. In addition, all models will include children's gender, and trial as control variables (based on Hepach et al., 2017). To test H1: Behavior and emotion co-emerge, the interaction of the factors distribution (within-subjects; equal or unequal), context (between-subjects; social or nonsocial) and age (z-transformed) will be included in Model 1a. Based on this hypothesis, we predict that children's upper body posture will, with age, show a decrease in the social context and on unequal trials. To test H2: Emotion precedes behavior, Model 2a will include the interaction of the factors context and distribution. Based on this hypothesis, we predict children will show a lower upper 


\section{EMOTIONS AND (UN)FAIRNESS IN CHILDREN}

body posture in the social context on unequal trials across the entire age range. In addition, Models $1 \mathrm{~b}$ and $2 \mathrm{~b}$ will examine whether children's change in upper body posture varied as a function of their distance from the Kinect camera (see Table 1 for an overview). Models 2a and $2 \mathrm{~b}$ will additionally include age as a control variable. The statistical models for the control analysis on children's change in lower-body posture will be identical to the final models for the change in children's upper body posture. It may be that the models suggest support for both $H 1$ and $H 2$. For instance, both the inclusion of the interaction of context and distribution in Model 2a as well as the inclusion of the interaction of context, distribution and age in Model 1a may improve model fit. In such a case, if the pattern for each of these interactions is in the predicted direction, we would conclude that both $H 1$ and $H 2$ have merit in explaining children's change in body posture.

To estimate the age of emergence of a difference between the two within-subjects conditions across social and nonsocial contexts, we will examine at which age $95 \%$ confidence intervals of the predicted values for the change in children's body posture are nonoverlapping (see also Blake et al., 2015 for a similar approach). To this end, the predicted values will be plotted with a line fitted with ordinary least squares. If more than one of the factors of interest improves model fit in the predicted direction, figures with the fitted values for each of the models will be examined to determine the age of emergence of a difference between the within-subjects conditions. The same approach will be adopted to estimate the age of emergence of a difference in the within-subjects conditions for the change in children's lower body posture, if children's lower-body posture systematically varies as a function of the experimental manipulations.

Table 1

Model Structure of the Statistical Models for the Body Posture Analysis
Model Fixed effect
Hypothesis 


\begin{tabular}{lll}
\hline 1a & Context $x$ distribution $x$ & H1: Emotion and behavior co-emerge \\
& age & \\
$1 \mathrm{~b}$ & Context $\mathrm{x}$ distribution $\mathrm{x}$ & Emotion and behavior co-emerge, \\
& age $\mathrm{x}$ distance & children's postural change varies across \\
& & distance \\
$2 \mathrm{a}$ & Context $\mathrm{x}$ distribution & H2: Emotion precedes behavior \\
& Context $\mathrm{x}$ distribution $\mathrm{x}$ & Emotion precedes behavior, children's \\
& distance & postural change varies across distance
\end{tabular}

Supplementary Analysis. In order to address the potential influence of block order on children's change in body posture, we will conduct a supplementary analysis by running all models including only the data children provided on the first block (only equal or only unequal trials). The results of this analysis will be considered exploratory and will not be used to directly address the hypotheses.

Behavioral measure of advantageous inequity aversion. To examine H3: Late emergence of behavior, which predicts that, children will begin to show a costly rejection of advantageous inequity at 7 to 9 years of age (Blake \& McAuliffe, 2011; Shaw \& Olson, 2012), we will run a logistic regression model with children's choice to accept or reject the $(4,1)$ offer as the dependent variable. Children's choices will be coded a $1=$ accept ("distribute the resources") or $0=$ reject ("leave in the boxes"). The main fixed effect of interest will be the interaction of the factors age (z-transformed) and context (betweensubjects; social or nonsocial). The significance of the predictors will be examined with the summary() function with the alpha level for statistical significance set at $p<.05$. We will plot the probability of rejection based on the model fitted values with associated $95 \%$ confidence intervals as a function of age across the two contexts with a fitted line using ordinary least squares. To estimate the age of emergence of children's rejection of advantageous inequity, we will estimate at what age $95 \%$ confidence intervals are non-overlapping across contexts. 
EMOTIONS AND (UN)FAIRNESS IN CHILDREN

\section{Pilot Study and Power Analysis}

We conducted a pilot study to ensure that the procedure was adequate for children within the anticipated age range (see also S3, Supplementary Materials). We piloted a version with a pseudo-randomized trial order, in which two equal or unequal trials were followed by the rest of the trials randomly, before deciding on the blocked trial order. Piloting was completed as soon as all procedural concerns were addressed-most importantly as soon as children understood the task and could follow the experimenters' instructions.

All models for the analysis of children's change in body posture were calculated with pilot data ( $\mathrm{N}=21$ children provided body posture data). As an index of effect size, we report $\Delta R_{m}{ }^{2}$ resulting from the difference in model fit between full models including all fixed and random effects, and null models including only the control variables and random effects without the fixed effects of interest (see Table 1). R-squared was calculated with the in Rpackage MuMin (Multi-model inference, Barton, 2019), and using the method described by Nakagawa \& Schielzeth (2013). These model comparisons yielded an average effect size of $\Delta R_{m}{ }^{2}=.065$ for the inclusion of the fixed effects of interest in Models $1 \mathrm{a}$ and $1 \mathrm{~b}$ and an average effect size $\Delta R_{m}{ }^{2}=.015$ for the inclusion of the fixed effects of interest Model 2a and 2b. Power analyses based on model comparisons were conducted with the R-package simr (Version 1.0.3, Green \& MacLeod, 2016), and indicated an average power of $1-\beta=1,95 \%$ CI [.9963 1] to detect effects of this magnitude with the specified sample size.

Based on our pilot data ( $\mathrm{N}=19$ children provided behavioral data) and Study 2 of McAuliffe et al. (2013), we assumed an effect size of $\mathrm{OR}=5.77(10 \%$ of rejections in younger children and $40 \%$ in older children in the social context) for the development of children's rejection of advantageous inequity. With the software G*Power (Faul, Erdfelder, Lang, \& Buchner, 2007), $1-\beta=.99$ power is achieved to detect an effect of this size for the analysis of children's behavior with the specified sample size. 
EMOTIONS AND (UN)FAIRNESS IN CHILDREN

\section{References}

App, B., McIntosh, D. N., Reed, C. L., \& Hertenstein, M. J. (2011). Nonverbal channel use in communication of emotion: How may depend on why. Emotion, 11(3), 603-617. https://doi.org/10.1037/a0023164

Barton, K. (2019) Mu-MIn: Multi-model inference. R Package Version 1.40.0. https://cran.rproject.org/web/packages/MuMIn

Bates, D., Mächler, M., Bolker, B., \& Walker, S. (2015). Fitting linear mixed-effects models using lme4. Journal of Statistical Software, 67(1), 1-48.

https://doi.org/10.18637/jss.v067.i01

Baumard, N., Mascaro, O., \& Chevallier, C. (2012). Preschoolers are able to take merit into account when distributing goods. Developmental Psychology, 48(2), 492-498. https://doi.org/10.1037/a0026598

Beck, S. R., \& Riggs, K. J. (2014). Developing thoughts about what might have been. Child Development Perspectives, 8(3), 175-179. https://doi.org/10.1111/cdep.12082

Blake, P. R., \& McAuliffe, K. (2011). “I had so much it didn't seem fair”: Eight-year-olds reject two forms of inequity. Cognition, 120(2), 215-224. https://doi.org/10.1016/j.cognition.2011.04.006

Blake, P. R., McAuliffe, K., Corbit, J., Callaghan, T. C., Barry, O., Bowie, A., ... Warneken, F. (2015). The ontogeny of fairness in seven societies. Nature, 528(7581), 258-261. https://doi.org/10.1038/nature15703

Corbit, J., McAuliffe, K., Callaghan, T. C., Blake, P. R., \& Warneken, F. (2017). Children's collaboration induces fairness rather than generosity. Cognition, 168, 344-356. https://doi.org/10.1016/j.cognition.2017.07.006

Dawes, C. T., Fowler, J. H., Johnson, T., McElreath, R., \& Smirnov, O. (2007). Egalitarian motives in humans. Nature, 446(7137), 794-796. https://doi.org/10.1038/nature05651

Dunham, Y., Durkin, A., \& Tyler, T. R. (2018). The development of a preference for 
EMOTIONS AND (UN)FAIRNESS IN CHILDREN

procedural justice for self and others. Scientific Reports, 8 . https://doi.org/10.1038/s41598-018-36072-1

Engelmann, J. M., \& Tomasello, M. (2019). Respect defended. Trends in Cognitive Sciences. https://doi.org/10.1016/j.tics.2019.06.001

Faul, F., Erdfelder, E., Lang, A.-G., \& Buchner, A. (2007). G*Power 3: A flexible statistical power analysis program for the social, behavioral, and biomedical sciences. Behavior Research Methods, 39(2), 175-191. https://doi.org/10.3758/BF03193146

Fehr, E., Bernhard, H., \& Rockenbach, B. (2008). Egalitarianism in young children. Nature, 454(7208), 1079-1083. https://doi.org/10.1038/nature07155

Fehr, E., \& Fischbacher, U. (2003). The nature of human altruism. Nature, 425(6960), 785791. https://doi.org/10.1038/nature02043

Gerdemann, S., Tippmann, J., Dietrich, B., Engelmann, J. M., \& Hepach, R. (2019). 5-yearold children show a lower body posture when they are unable to help. Manuscript in preparation.

Green, P., \& MacLeod, C. J. (2016). SIMR: An R package for power analysis of generalized linear mixed models by simulation. Methods in Ecology and Evolution, 7(4), 493-498. https://doi.org/10.1111/2041-210X.12504

Güth, W., Schmittberger, R., \& Schwarze, B. (1982). An experimental analysis of ultimatum bargaining. Journal of Economic Behavior \& Organization, 3(4), 367-388. https://doi.org/10.1016/0167-2681(82)90011-7

Hamann, K., Bender, J., \& Tomasello, M. (2014). Meritocratic sharing is based on collaboration in 3-year-olds. Developmental Psychology, 50(1), 121-128. https://doi.org/10.1037/a0032965

Hamann, K., Warneken, F., Greenberg, J. R., \& Tomasello, M. (2011). Collaboration encourages equal sharing in children but not in chimpanzees. Nature, 476(7360), 328331. https://doi.org/10.1038/nature10278 
EMOTIONS AND (UN)FAIRNESS IN CHILDREN

Henrich, J., Ensminger, J., McElreath, R., Barr, A., Barrett, C., Bolyanatz, A., .. Ziker, J. (2010). Markets, religion, community size, and the evolution of fairness and punishment. Science, 327(5972), 1480-1484. https://doi.org/10.1126/science.1182238

Henrich, J., McElreath, R., Barr, A., Ensminger, J., Barrett, C., Bolyanatz, A., ... Ziker, J. (2006). Costly punishment across human societies. Science, 312(5781), 1767-1770. https://doi.org/10.1126/science.1127333

Hepach, R., Vaish, A., \& Tomasello, M. (2015). Novel paradigms to measure variability of behavior in early childhood: Posture, gaze, and pupil dilation. Frontiers in Psychology, 6. https://doi.org/10.3389/fpsyg.2015.00858

Hepach, R., Vaish, A., \& Tomasello, M. (2017). The fulfillment of others' needs elevates children's body posture. Developmental Psychology, 53(1), 100-113. https://doi.org/10.1037/dev0000173

House, B. R., Henrich, J., Brosnan, S. F., \& Silk, J. B. (2012). The ontogeny of human prosociality: Behavioral experiments with children aged 3 to 8. Evolution and Human Behavior, 33(4), 291-308. https://doi.org/10.1016/j.evolhumbehav.2011.10.007

House, B. R., Kanngiesser, P., Barrett, H. C., Broesch, T., Cebioglu, S., Crittenden, A. N., ... Silk, J. B. (2019). Universal norm psychology leads to societal diversity in prosocial behaviour and development. Nature Human Behaviour, 1-9. https://doi.org/10.1038/s41562-019-0734-z

House, B. R., Silk, J. B., Henrich, J., Barrett, H. C., Scelza, B. A., Boyette, A. H., ... Laurence, S. (2013). Ontogeny of prosocial behavior across diverse societies. Proceedings of the National Academy of Sciences, 110(36), 14586-14591. https://doi.org/10.1073/pnas.1221217110

Keltner, D., \& Harker, L. (1998). The forms and functions of the nonverbal signal of shame. In Series in Affective Science. Shame: Interpersonal behavior, psychopathology, and culture (pp. 78-98). New York, NY, US: Oxford University Press. 
EMOTIONS AND (UN)FAIRNESS IN CHILDREN

Kochanska, G., Gross, J. N., Lin, M.-H., \& Nichols, K. E. (2002). Guilt in young children: Development, determinants, and relations with a broader system of standards. Child Development, 73(2), 461-482.

Krettenauer, T., Malti, T., \& Sokol, B. (2008). The development of moral emotions and the happy victimizer phenomenon: A critical review of theory and applications. European Journal of Developmental Science, 2(3), 221-235.

Keller, M., Lourenço, O., Malti, T., \& Saalbach, H. (2003). The multifaceted phenomenon of "happy victimizers": A cross-cultural comparison of moral emotions." British Journal of Developmental Psychology, 21(1), 1-18. https://doi.org/10.1348/026151003321164582

Lewis, M., Alessandri, S. M., \& Sullivan, M. W. (1992). Differences in shame and pride as a function of children's gender and task difficulty. Child Development, 63(3), 630-638. https://doi.org/10.2307/1131351

Lewis, M. (2007). Self-conscious emotional development. In The self-conscious emotions: Theory and research (pp. 134-149). New York, NY, US: Guilford Press.

LoBue, V., Nishida, T., Chiong, C., DeLoache, J. S., \& Haidt, J. (2011). When getting something good is bad: Even three-year-olds react to inequality. Social Development, 20(1), 154-170. https://doi.org/10.1111/j.1467-9507.2009.00560.x

Loewenstein, G. F., Thompson, L., \& Bazerman, M. H. (1989). Social utility and decision making in interpersonal contexts. Journal of Personality and Social Psychology, 57(3), 426-441. https://doi.org/10.1037/0022-3514.57.3.426

McAuliffe, K., Blake, P. R., Kim, G., Wrangham, R. W., \& Warneken, F. (2013). Social influences on inequity aversion in children. PLOS ONE, 8(12), e80966. https://doi.org/10.1371/journal.pone.0080966

McAuliffe, K., Blake, P. R., Steinbeis, N., \& Warneken, F. (2017). The developmental foundations of human fairness. Nature Human Behaviour, 1(2), 0042. 
EMOTIONS AND (UN)FAIRNESS IN CHILDREN

https://doi.org/10.1038/s41562-016-0042

Moore, B. S., Underwood, B., \& Rosenhan, D. L. (1973). Affect and altruism. Developmental Psychology, 8(1), 99-104. https://doi.org/10.1037/h0033847

Nakagawa, S., \& Schielzeth, H. (2013). A general and simple method for obtaining R2 from generalized linear mixed-effects models. Methods in Ecology and Evolution, 4(2), 133-142. https://doi.org/10.1111/j.2041-210x.2012.00261.x

Nunner-Winkler, G., \& Sodian, B. (1988). Children's understanding of moral emotions. Child Development, 59(5), 1323-1338. https://doi.org/10.2307/1130495

O’Connor, E., McCormack, T., \& Feeney, A. (2012). The development of regret. Journal of Experimental Child Psychology, 111(1), 120-127. https://doi.org/10.1016/j.jecp.2011.07.002

Olson, K. R., \& Spelke, E. S. (2008). Foundations of cooperation in young children. Cognition, 108(1), 222-231. https://doi.org/10.1016/j.cognition.2007.12.003

Pons, F., Harris, P. L., \& Rosnay, M. de. (2004). Emotion comprehension between 3 and 11 years: Developmental periods and hierarchical organization. European Journal of Developmental Psychology, 1(2), 127-152.

https://doi.org/10.1080/17405620344000022

Sanfey, A. G., Rilling, J. K., Aronson, J. A., Nystrom, L. E., \& Cohen, J. D. (2003). The neural basis of economic decision-making in the Ultimatum Game. Science (New York, N.Y.), 300(5626), 1755-1758. https://doi.org/10.1126/science.1082976

Stipek, D., Recchia, S., McClintic, S., \& Lewis, M. (1992). Self-evaluation in young children. Monographs of the Society for Research in Child Development, 57(1), i-95. https://doi.org/10.2307/1166190

Shaw, A., \& Olson, K. R. (2012). Children discard a resource to avoid inequity. Journal of Experimental Psychology: General, 141(2), 382-395.

https://doi.org/10.1037/a0025907 
Sheskin, M., Bloom, P., \& Wynn, K. (2014). Anti-equality: Social comparison in young children. Cognition, 130(2). https://doi.org/10.1016/j.cognition.2013.10.008

Smith, C. E., Blake, P. R., \& Harris, P. L. (2013). I should but I won't: Why young children endorse norms of fair sharing but do not follow them. PLOS ONE, 8(3), e59510. https://doi.org/10.1371/journal.pone.0059510

Steinbeis, N. (2018). Taxing behavioral control diminishes sharing and costly punishment in childhood. Developmental Science, 21(1), e12492. https://doi.org/10.1111/desc.12492

Steinbeis, N., Bernhardt, B. C., \& Singer, T. (2012). Impulse control and underlying functions of the left DLPFC mediate age-related and age-independent individual differences in strategic social behavior. Neuron, 73(5), 1040-1051. https://doi.org/10.1016/j.neuron.2011.12.027

Tracy, J. L., \& Matsumoto, D. (2008). The spontaneous expression of pride and shame: Evidence for biologically innate nonverbal displays. Proceedings of the National Academy of Sciences of the United States of America, 105(33), 11655-11660. https://doi.org/10.1073/pnas.0802686105

Tomasello, M., \& Vaish, A. (2013). Origins of human cooperation and morality. Annual Review of Psychology, 64, 231-255. https://doi.org/10.1146/annurev-psych-113011143812

Ulber, J., Hamann, K., \& Tomasello, M. (2017). Young children, but not chimpanzees, are averse to disadvantageous and advantageous inequities. Journal of Experimental Child Psychology, 155, 48-66. https://doi.org/10.1016/j.jecp.2016.10.013

Vaish, A., Carpenter, M., \& Tomasello, M. (2016). The early emergence of guilt-motivated prosocial behavior. Child Development, 87(6), 1772-1782. https://doi.org/10.1111/cdev.12628

Wallbott, H. G. (1998). Bodily expression of emotion. European Journal of Social Psychology, 28(6), 879-896. https://doi.org/10.1002/(SICI)1099- 
EMOTIONS AND (UN)FAIRNESS IN CHILDREN

0992(1998110)28:6<879::AID-EJSP901>3.0.CO;2-W

Weisberg, D. P., \& Beck, S. R. (2012). The development of children's regret and relief.

Cognition \& Emotion, 26(5), 820-835. https://doi.org/10.1080/02699931.2011.621933

Witkower, Z., \& Tracy, J. L. (2018). Bodily communication of emotion: Evidence for extrafacial behavioral expressions and available coding systems. Emotion Review, 1754073917749880. https://doi.org/10.1177/1754073917749880 